\title{
IPTEK BAGI MASYARAKAT: PENERAPAN IOT DENGAN SMARTPHONE PADA SMK PLUS AL-MUSYARROFAH SEBAGAI UPAYA PENCAPAIAN SUSTAINABLE DEVELOPMENT GOAL TUJUAN 4 TARGET 3
}

\author{
Mohamad Salman Alfarisi \\ Manajemen Informatika, Fakultas Teknologi Informasi, Universitas Budi Luhur \\ J1. Ciledug Raya, Petukangan Utara, Jakarta, 12260 \\ E-mail : salman.alfarisi@budiluhur.ac.id
}

\begin{abstract}
ABSTRAK
Sustainable Development Goals (SDGs) memiliki 17 goals dan 169 target, salah-satu fokus SGDs adalah tujuan nomor 4, yaitu menjamin kualitas pendidikan yang adil dan inklusif serta mempromosikan kesempatan belajar seumur hidup bagi semua. Sasaran dari tujuan ini adalah menjamin akses yang merata untuk perempuan dan laki-laki untuk mendapatkan kualitas teknis, kejuruan dan pendidikan tinggi yang terjangkau, termasuk universitas.

SMK Plus Al-Musyarrofah memiliki dua Jurusan yaitu Teknik Komputer dan Jaringan (TKJ) serta Tata Niaga (TN). Setiap siswa Jurusan TKJ mendapatkan matapelajaran sesuai dengan jurusannya yaitu Perakitan PC, K3LH, Teknik Elektronika, Instalas PC/Pengoperasian PC, Perwatan PC dan Perbaikan Peripheral, Instalasi Software, Instalasi Perangkat Jaringan Lokal, Pengoperasian PC Tersambung Jaringan, Instalasi SOJ Berbasis GUI. Mata pelajaran yang diperoleh tersebut menitikberatkan pada hardware dan software sebagai pendukung teknologi, oleh karena itu perlu ditambahkan pengetahuan tambahan seperti Internet of Things (IOT) dengan memanfaatkan smartphone. Dengan tambahan pengetahuan IoT Siswa SMK Plus Al-Musyarrofah dapat memanfaatkan secara optimal smartphone dalam kegiatan belajar mengajar seperti IFTTT, Marcro Droid dan Tasker.
\end{abstract}

Kata Kunci: Sustainable Development Goals, Kualitas Pendidikan, Internet of Thing, Iot, Smartphone.

\section{PENDAHULUAN}

Setelah sukses melaksanakan Millenium Development Goals (MDGs), United Nations (UN) atau Persatuan Bangsa-Bangsa (PBB) kini mencanangkan Sustainable Development Goals (SDGs) sebagai program lanjutannya. SDGs atau yang dikenal juga sebagai "Global Goals" merupakan suatu ajakan bersama (universal) untuk melakukan aksi dengan tujuan mengakhiri kemiskinan, melindungi bumi dan menjamin bahwa semua orang dapat menikmati hidup yang damai dan sejahtera. SDGs menambahkan area baru dalam prioritas yang akan dicapai seperti perubahan iklim, kesetaraan ekonomi, konsumsi yang berkelanjutan, keadilan dan perdamaian (www.UNDP.org diakses 10 November 2016).

Fokus kegiatan ini adalah tujuan dengan nomor 4 yaitu menjamin kualitas pendidikan yang adil dan inklusif serta mempromosikan kesempatan belajar seumur hidup bagi semua, tujuan kegiatan ini terdiri dari beberapa sasaran yang salah satunya merupakan sasaran yang ingin dicapai dari kegiatan ini, yaitu menjamin akses yang merata untuk perempuan dan laki-laki untuk mendapatkan kualitas teknis, kejuruan dan pendidikan tinggi yang terjangkau, termasuk universitas. Untuk meningkatkan kualitas teknis salah satunya adalah dengan memanfaatkan teknologi yang sudah ada, yaitu Internet of Things (IoT)
Menurut Kementerian Komunikasi dan Informatika (Kominfo) Republik Indonesia memperkirakan pada tahun 2018 jumlah aktif pengguna smartphone di Indonesia bisa mencapai 100 juta orang (kominfo.go.id diakses 28 November 2016). Sudah lebih dari 88 juta penduduk Indonesia menggunakan internet, 93\% dari pengguna internet mengakses internet melalaui smartphone dengan aplikasi mobile yang sering diakses antara lain WhatsApp, YouTube, Line, Facebook, Gmail, dan Instagram. (arenalte.com diakses 28 November 2016).

SMK Plus Al-Musyarrofah memiliki dua Jurusan yaitu Tata Niaga (TN) serta Teknik Komputer dan Jaringan (TKJ). Berdasarkan pengamatan, SMK Plus AlMusyarrofah belum secara optimal memanfaatkan Internet of things dengan smartphone, sehinga perlu dibekali pemahaman Internet of Things. Diharapkan setelah mengikuti kegiatan ini siswa SMK Plus AlMusyarrofa dapat pengetahuan baru dalam bidang teknologi informasi khususnya Internet of Things dengan menggunakan smartphone, guna menunjang produktivitas sehari-hari. 


\section{RUANG LINGKUP}

Cakupan permasalahan dari kegiatan ini adalah pembekalan pengetahuan kepada para siswa tentang Internet of Things dengan memanfaatkan smartphone.

Aplikasi yang digunakan dalam pemanfaatan IoT adalah Aplikasi Android yaitu IFTTT, MacroDroid dan Tasker.

Setelah mengikuti kegiatan ini siswa secara optimal dapat menggunakan Internet of Things dengan menggunakan smartphone yang dimilikinya dalam kegiatan belajar mengajar.

\section{BAHAN DAN METODE}

Metode dalam kegiatan ini adalah sebagai berikut:

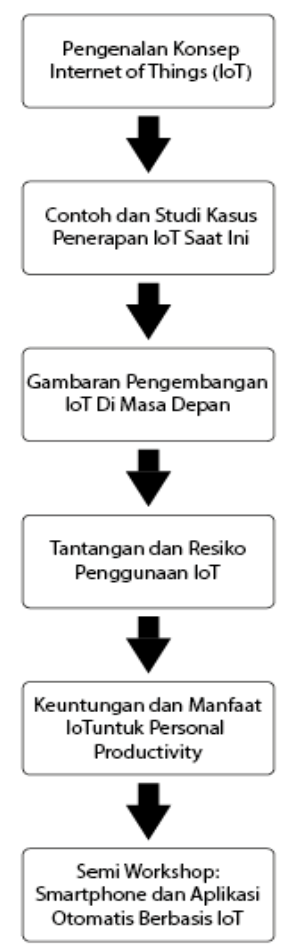

\section{Gambar 1. Presentasi Mobile IoT}

Tahap awal adalah pengenalan konsep internet of things (IoT), dilanjutkan dengan contoh dan studi kasus penerapan IoT saat ini, setelah itu penulis memaparkan gambaran pengembangan IoT di masa depan dengan membahas tantangan dan resiko penggunaan IoT, kemudian menjelaskan keuntungan dan manfaat IoT untuk personal productivity dan diakhiri dengan mengadakan semi workshop: smartphone dan aplikasi otomatis berbasis $I o T$

\section{PEMBAHASAN}

Siswa diberikan materi Internet of Things (IoT) seperti:

1. Pengenalan konsep IoT

Memaparkan tentang konsep Internet of Things (IoT) sebagai teknologi yang mengubah gaya hidup masyarakat pengguna smartphone. IoT bukan lagi teknologi yang asing, melainkan sebuah konsep modern yang mulai merubah gaya hidup masyarakat secara perlahan, tapi pasti.

\section{Contoh dan Studi Kasus IoT}

Contohnya seperti pemanfaatan benda elektronik yang memiliki akses wireless dan konektifitas dengan smartphone, sehingga menyebabkan banyak muncul istilah baru, seperti SmartTV, SmartHome, SmartCar, SmartCity dan lain sebagainya.

3. Gambaran Pengembangan IoT dimasa depan

Memaparkan beberapa perusahaan dan pengembang teknologi IoT baik dari Silicon Valley (US), maupun dari Startup lokal di Indonesia, berserta ruang lingkup pengembangannya seperti IoT untuk bidang pertanian, kesehatan, transportasi dan fintech (keuangan \& Bisnis).

4. Tantangan dan Resiko Penggunaan IoT

Materi tentang tantangan dan resiko dari pemanfaatan IoT diberikan karena IoT merupakan sebuah konsep dimana suatu objek yang memiliki kemampuan untuk mentransfer data melalui jaringan tanpa memerlukan interaksi manusia ke manusia atau manusia ke komputer.

Hal ini menyebabkan pemanfaatan IoT memiliki celah keamanan yang menjadi tantangan dimasa depan seperti, kejahatan cyber, pencurian identitas dan kartu kredit.

5. Keuntungan dan Manfaat IoT untuk Personal Productivity
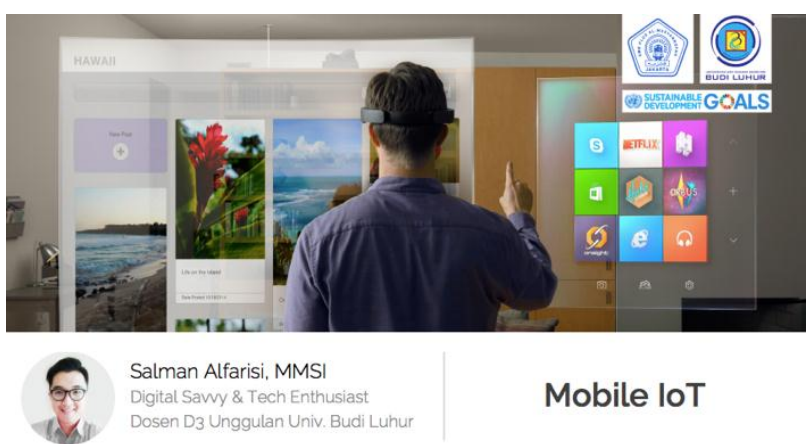

Gambar 2. Presentasi Mobile IoT

Dapat dilihat pada gambar 1, pemanfaatan IoT pada kegiatan ini dikhususkan untuk produktifitas siswa/i dan guru dengan menggunakan 3 Aplikasi mobile berbasis Android, mengimplementasikan IoT yaitu IFTTT, MacroDroid dan Tasker. 3 Aplikasi ini merupakan aplikasi yang gratis dan bisa diinstal oleh para pengguna smartphone Android 


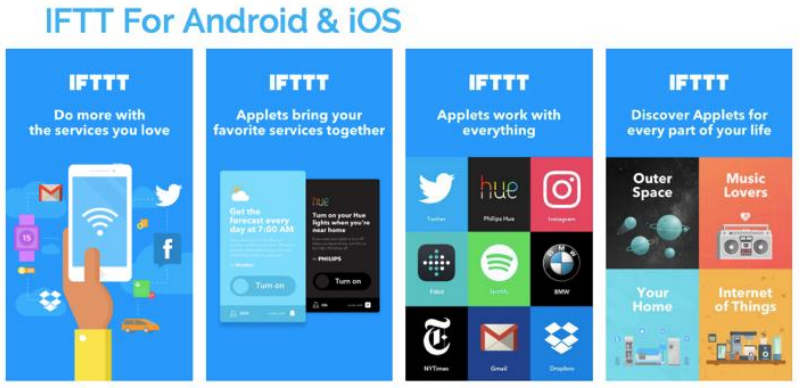

Gambar 3. IFTT

Pada gambar 2, IFTTT atau If This Then That merupakan aplikasi smarphone yang bisa menghubungkan berbagaimacam servis platform dan data hardware dengan pengaturan yang bisa diaktifkan melalui smartphone. Aplikasi IFTTT memungkinkan penggunanya untuk menambahkan fungsi smartphone layaknya sebuah remote untuk mengendalikan barang elektronik yang memiliki koneksi bluetooth dan data internet. Selain hardware, IFTTT juga bisa digunakan untuk menghubungkan servis platform seperti social media.

MacroDroid merupakan aplikasi smarphone android yang digunakan untuk men-trigger fungsi tertentu dalam smartphone. Contoh dengan memasukan fungsi waktu tertentu MacroDroid akan melakukan sebuah tindakan, semisal setting waktu makan siang untuk membuka aplikasi pemesan makanan.

Tasker merupakan aplikasi android yang fungsinya untuk mengotomatisasikan sebuah pekerjaan (task), dengan beberapa perintah sederhana dalam aplikasinya. Contohnya mengaktifkan WiFi pada smartphone secara otomatis saat pengguna ada di rumah dengan memberikan perintah location trigger pada Tasker.

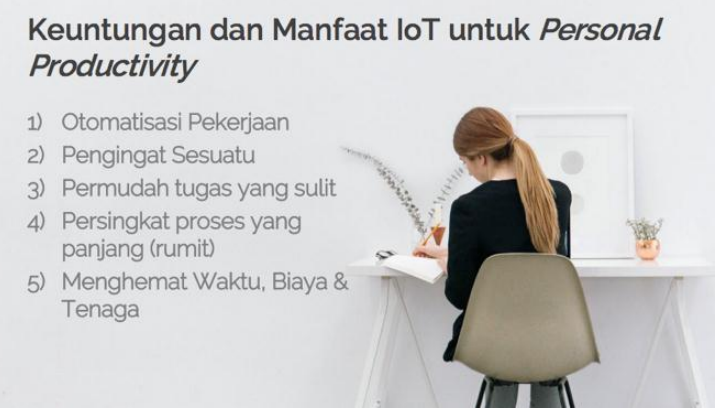

\section{Gambar 4. Keuntungan Mobile IoT}

Dapat dilihat dari gambar 3, keuntungan dari penggunaan aplikasi Android berkonsep IoT adalah agar siswa dapat langsung mempraktekan IoT didalam kehidupan mereka, untuk mempermudah tugas, menghemat waktu dan otomatisasi, semisal contoh kecil; mematikan lampu atau AC secara otomatis saat user pergi keluar ruangan dengan smartphonenya.

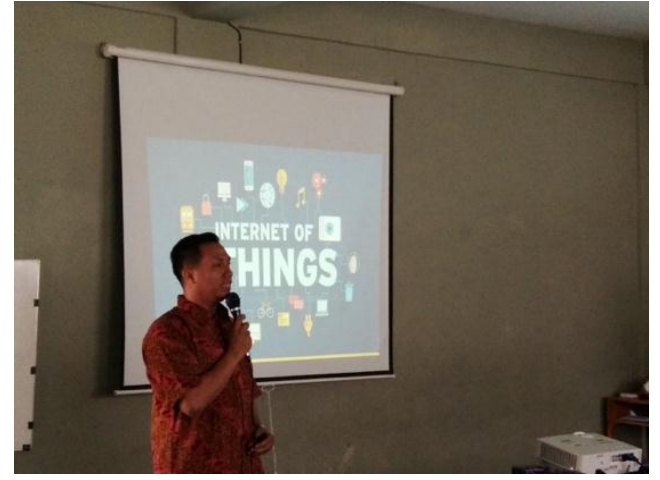

Gambar 5. Workshop Mobile IoT

6. Semi Workshop: Smartphone dan Aplikasi Otomatis Berbasis IoT

Siswa diminta untuk menginstal aplikasi berbasis IoT dan membuat "applet" (otomatisasi IoT) pada smartphone masing-masing. Tujuannya adalah agar siswa dapat menerapkan konsep IoT pada keseharian mereka dengan memperaktekan langsung di smartphone yang mereka miliki.

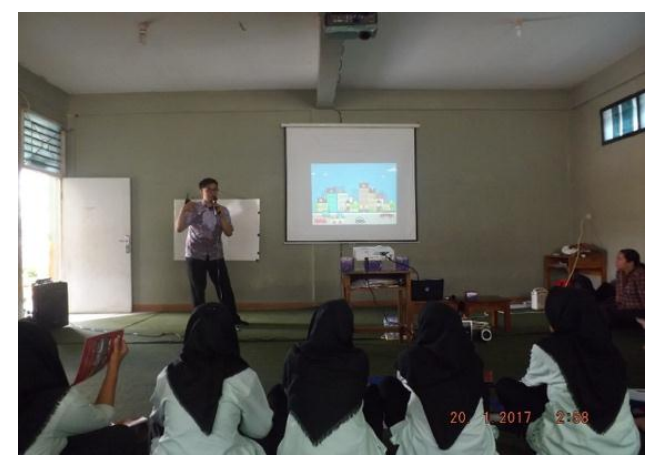

\section{Gambar 6. Praktek Memanfaatkan Mobile IoT}

Target luaran dari kegiatan ini telah tercapai yaitu memberikan pengetahuan kepada siswa-siswi SMK AlMusyaroffah tentang IoT dan juga memberikan pemahaman tentang pemanfaatan IoT dengan menggunakan smartphone.

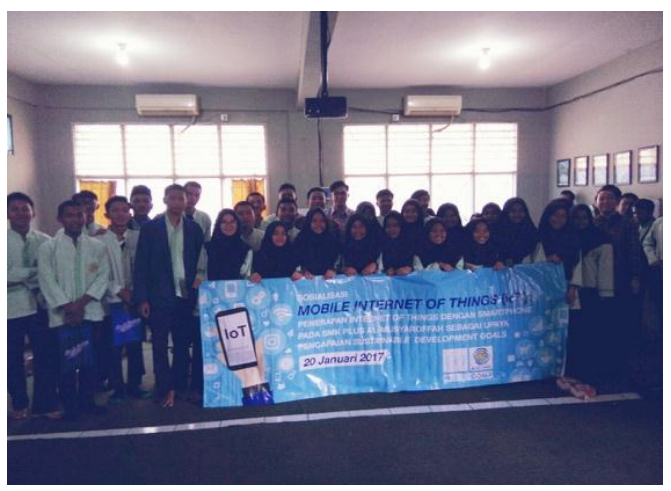

Gambar 7. Peserta Kegiatan Mobile IoT 
Dalam gambar 7. merupakan para peserta kegiatan Mobile IoT. Penggunaan smartphone berperan penting dalam pemanfaatan IoT dan sebagian besar siswa merupakan golongan usia yang sering menggunakan smartphone dan memahami cara penggunaanya, oleh karena itu bentuk kegiatan ini yang merupakan kegiatan dalam pemanfaatan IoT menggunakan smartphone sangat dibutuhkan sehingga smartphone tidak hanya dimanfaatkan sebagai alat komunikasi saja tetapi juga dapat dimanfaatan untuk keperluan IoT yang dapat menguntungkan bagi siswa-siswa dalam proses belajar.

\section{KESIMPULAN}

Kegiatan ini memberikan kesadaran bagi siswa-siswi tentang peran penggunaan smartphone sebagai penerapan IoT. Selama ini smartphone yang digunakan oleh siswa-siswi hanya sebatas untuk berkomunikasi saja, dengan kegiatan ini smartphone mempunyai manfaat yang lain yaitu untuk mendukung pemanfaatan IoT.

Pemanfaatan IoT dengan smartphone dapat membantu siswa-siswi baik dalam kehidupan sehari-hari atau dalam kegiatan belajar di sekolah salah satunya dengan memanfaatkan aplikasi IFTTT, MacroDroid dan Tasker.

Pemanfaatan aplikasi smartphone yang memungkinkan siswa untuk memahami dan mempraktekkan IoT seperti, IFTTT untuk menghubungkan samrtphone dengan platform dan hardware layaknya sebuah remote, MacroDroid untuk men-trigger tindakan berdasarkan keinginan user dan Tasker untuk mengotomatisasi pekerjaan lewat smarphone, akhirnya siswa dapat mempraktekan konsep IoT lewat smarphonenya dalam kegiatan belajar mengajar.

Materi IoT yang telah diberikan pada kegiatan ini telah memberikan manfaat kepada banyak pihak seperti siswa, guru, dosen, maupun sekolah. Bagi siswa dan guru dapat menambah pengetahuan tentang IoT, serta pemanfaatannya dengan menggunakan smartphone; bagi sekolah yang merupakan wadah untuk mencerdaskan masyarakat dalam bidang pendidikan sehingga dapat mensejahterakan kehidupan bangsa dalam bidang sosial dan teknologi.

Dengan kegiatan ini telah terlaksananya pencapaian tujuan Sustainable Development Goals (SDGs) nomor 4, yaitu menjamin kualitas pendidikan yang adil dan inklusif serta mempromosikan kesempatan belajar bagi semua, terutama target dari kegiatan ini yaitu siswa/i SMK Plus Al-Musyarrofah.

\section{SARAN}

Diperlukannya bentuk kerjasama yang lebih luas, semisal mengajak elemen masyarakat dan pemerintah untuk bersama-sama meningkatkan produktivitas dengan pemahaman mobile IoT, terutama karena pengguna smartphone di masyarakat semakin banyak. Juga untuk menjangkau jumlah peserta lebih besar, guna mencapai sasaran yang lebih optimal terkait tentang Mobile Internet of Things (IoT) dan pemanfaatan IoT dengan smartphone.

\section{DAFTAR PUSTAKA}

Bagheri, M. and Haghighi Movahed, S., 2016, October. The effect of the Internet of Things (IoT) on education business model. In 2016 12th International Conference on Signal-Image Technology \& Internet-Based Systems (SITIS) (pp. 435-441). IEEE Computer Society.

Data Pengguna Smartphone 2016 di Indonesia, http://arenalte.com/berita/industri/data-gfk-terbaru2016-pengguna-smartphone-indonesia/ (diakses tanggal 28 November 2016)

Gubbi, J., Buyya, R., Marusic, S. and Palaniswami, M., 2013. Internet of Things (IoT): A vision, architectural elements, and future directions. Future generation computer systems, 29(7), pp.1645-1660.

He, J., Lo, D.C.T., Xie, Y. and Lartigue, J., 2016, October. Integrating Internet of Things (IoT) into STEM undergraduate education: Case study of a modern technology infused courseware for embedded system course. In 2016 IEEE Frontiers in Education Conference (FIE) (pp. 1-9). IEEE.

Indonesia Raksasa Teknologi Digital Asia, https://kominfo.go.id/content/detail/6095/indonesiaraksasa-teknologi-digital-asia/0/sorotan_media (diakses tanggal 28 November 2016)

Lee, I. and Lee, K., 2015. The Internet of Things (IoT): Applications, investments, and challenges for enterprises. Business Horizons, 58(4), pp.431-440.

Madakam, S., Ramaswamy, R. and Tripathi, S., 2015. Internet of Things (IoT): A literature review. Journal of Computer and Communications, 3(05), p.164.

Penerapan Internet oft Things di Indonesia, http://arenalte.com/berita/industri/ini-penerapaninternet-of-things-indonesia/ (diakses tanggal 28 November 2016)

SDGs, https://sustainabledevelopment.un.org/sdg16 diakses 10 November 2016

UNDP .2015.. Konvergensi Agenda Pembangunan Nawa Cita, RPJM, dan SDGs, Jakarta: UNDP Indonesia

\section{UCAPAN TERIMA KASIH}

Terimakasih kepada pimpinan, guru dan siswa/i SMK Plus Al-Musyarrofah yang telah memberikan

kesempatan penulis untuk melaksanakan kegiatan ini. Terimaksih juga penulis ucapkan kepada rekan-rekan dosen Universitas Budi Luhur yang telah membimbing baik di lapangan, maupun dipenulisan. 